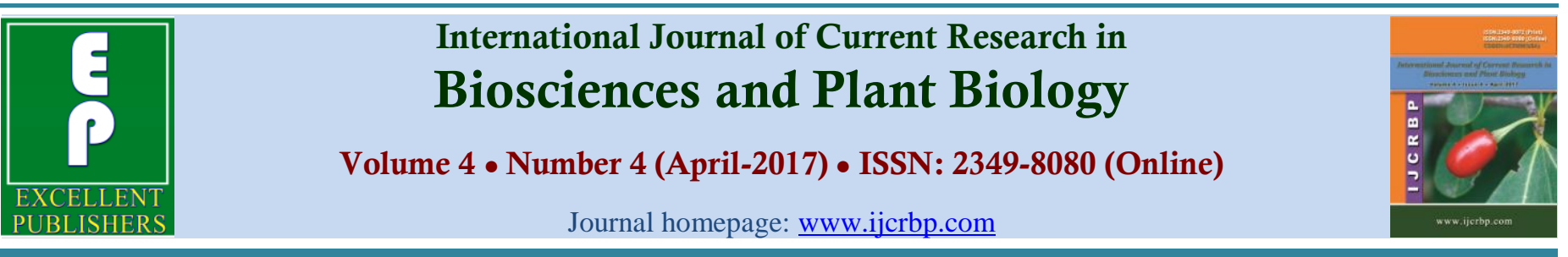

\title{
Influence of Some Factors on In Vitro Gas Production of Different Feed Groups and Possibilities for Its Prediction
}

\author{
Evgeni Videv', Jivko Krastanov, Staika Laleva', Nikolay Oblakov², Teodora Angelova1, Daniela \\ Yordanova $^{1}$, Georgi Kalaydzhiev ${ }^{1 *}$ and Magdalena Oblakova ${ }^{1}$
}

\author{
${ }^{1}$ Agricultural Institute, Stara Zagora, Bulgaria \\ ${ }^{2}$ Free Scientific Advisor, Stara Zagora, Bulgaria
}

*Corresponding author.

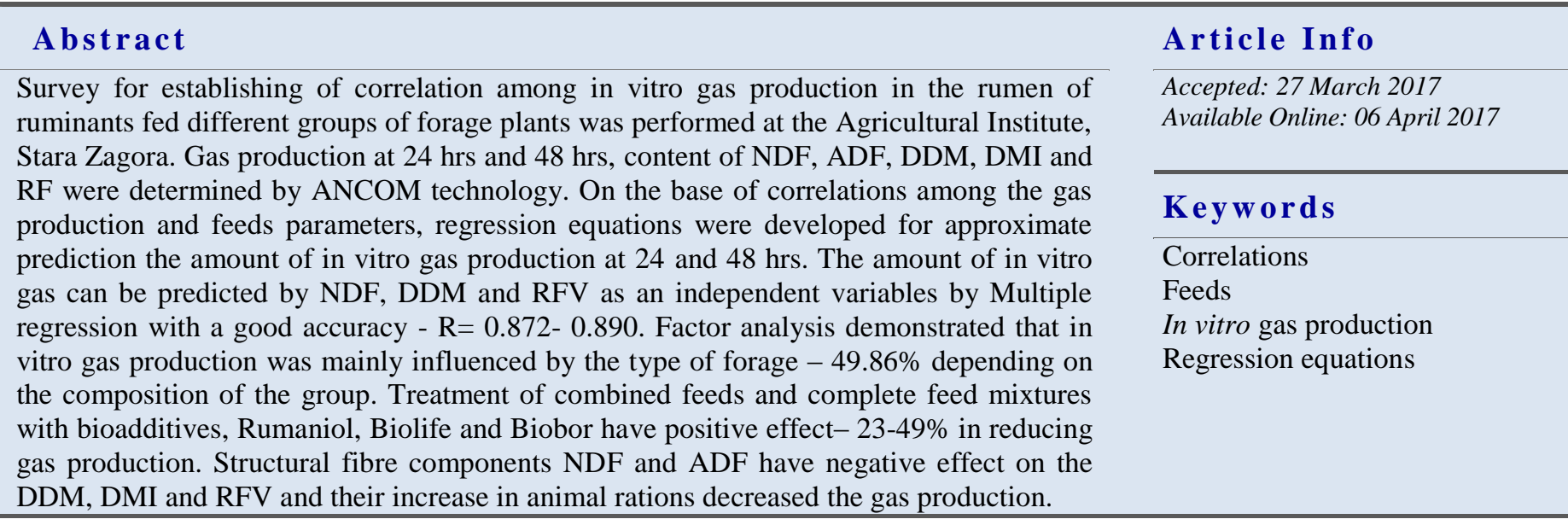

\section{Introduction}

The production of gas in the rumen of ruminants and gas emissions in the atmosphere depend on numerous factors. The amount of produced gas and production rate is associated with specific parameters of feeds such as chemical composition (organic matter content), feed morphological structure (content of structural fibrous components) and the rate of degradation. All these factors are important for predicting the approximate amount of produced gas and optimization of animal rations in order to reduce gaseous emissions. According to Johnson and Johnson (1995), feed consumption, dry matter intake (DMI) (Reynolds et al., 2010; Tamburini et al., 2010), the type and level of fermentable carbohydrates (Ellis et al., 2007), technological feed processing, lipid supplements (Grainger and Beauchemin, 2011) and management practices aimed at altering microbial communities in ruminants (protozoa and methanogens counts) (Odongo et al., 2007) could reduce methane production, which is mainly dependent on carbohydrate (structural fibrous components) and volatile fatty acids contents. The type and quality of feeds (lower or higher content of soluble carbohydrates) could influence methane production (Beauchemin et al., 2008). 
The main approach for correction of this problem is the supplementation of ruminant rations with feed ingredients in order to optimize rumen fermentation and decrease green house gas emissions - methane $\left(\mathrm{CH}_{4}\right)$ and carbon dioxide $\left(\mathrm{CO}_{2}\right)$ in the atmosphere. The inclusion of agro-industrial products in ruminant feeds could modify fatty acid profile of milk depending on the inclusion level, chemical composition and nutritional value of feeds (Leiber et al., 2005; Vasta et al., 2008; Molina-Alcaide et al., 2010). In dairy cows, lauric acid could be added to rations in order to decrease methane emissions (Külling et al., 2002).

The prediction of feed intake of animals - an important element of ruminant nutrition - is of particular importance (Minson, 1990). Practically, the prediction of roughage intake is still a problem (Blümmel and Becker, 1997). The determination of factors influencing the metabolism in the digestive tract of ruminants and formulation of parameters for evaluation of its efficiency are of utmost significance. The present study was designed to investigate correlative and regression relationships between in vitro green house gas production in the fore stomachs of ruminants $\left(\mathrm{CH}_{4}\right.$ and $\mathrm{CO}_{2}$ ) and the degradation of different feeds, feed additives and rumen modulators, the composition, digestibility and consumption of feeds.

\section{Materials and methods}

Samples of different types of feeds were collected from different regions of the country. All samples, containing feed and rumen content from fistulated animals, fed diet formulated from the studied feeds, were incubated in

\section{Ankom F57 filterbags (ANKOM Technology} Corporation, Fairport, NY, USA). The amount of produced gas from the different feeds was determined with GasProductionSystem ANCOM RF /Ankom ${ }^{\circledR}$, Tech. Co., Fairport, NY, USAafter 24 and 48 hrs.

Neutral detergent fibre (NDF, \%) and acid detergent fibre (ADF, \%) were determined by means of Ankom F57 filterbags (ANKOM Technology Corporation, Fairport, NY, USA).

The relative feed value - RFV was calculated on the basis of dry matter digestibility and dry matter intake, compared to the relative feed value of alfalfa (Jeranyama and Garcia, 2004; Ward and de Ondarza, 2008).

All experimental data were submitted to statistical analysis using SYSTAT 12@software (Copyright 2007, SYSTAT Software, Inc. AllRightsReserved).

\section{Results and discussion}

The analysis of the amount of gas produced after feeding 11 types of feeds with different structure and composition (grains, meals, straw, fresh feeds, silages, hays, haylages, compound feeds, compound feeds+supplements, total mixed rations with and without supplements) showed that on the average, the $24 \mathrm{hr}$ gas production was $212.79 \mathrm{ml}$, while $48 \mathrm{hrs}$ gas production was $257.97 \mathrm{ml}$ (Table 1). The inter-group difference was very large with minimum value ranging between 45.9 and 80.00 ( $24 \mathrm{hrs}$ ) and between 503.9 and 569.1 (48 hrs). The substantial difference was due to the specific structure of feeds and their chemical composition.

Table 1. Average gas production on the $24^{\text {th }}$ and $48^{\text {th }}$ hr from 11 feed groups, $\mathrm{n}=105$.

\begin{tabular}{llll}
\hline Feed groups & GP 24 h - Means & GP 48 h - Means & \% GP 48 h/GP 24 h \\
\hline For all groups & $\mathbf{2 1 2 . 7 9}$ & $\mathbf{2 5 7 . 9 7}$ & $\mathbf{1 2 1 . 2 3}$ \\
SD & 96.97 & 102.22 & \\
CV & 9402.4 & 10449.6 & \\
Min & $\mathbf{4 5 . 9}$ & $\mathbf{8 0 . 1 0}$ & \\
Max & $\mathbf{5 0 3 . 9}$ & $\mathbf{5 6 9 . 1}$ & \\
SE & 4.47 & 3.87 & \\
\hline
\end{tabular}

The composition of feeds, digestibility, consumption and relative feed values also varied within broad ranges: for acid-detergent fibre ADF\%: from 4.4 to 57.8; for neutral-detergent fibre NDF\%: from 8.6 to78.4; digestible dry matter DDM: from 36.6 to $85.5 \%$; for dry matter intake DMI: from 1.5 to 13.9 and for relative feed value RFV: from 52.1 to 923.6 (Table 2).
The considerable variations in gas production and feed parameters demonstrated a wide range of studied parameters and suggested the calculation of correlative and regression relationships marking the trends in the changes of dependent and independent variables involved in feed conversion and amount of produced green house gases. 
Table 2. Composition, digestibility and relative feed value- average for all studied groups of feeds, $\mathrm{n}=105$.

\begin{tabular}{llllll}
\hline Feed groups & ADF \% & NDF \% & DDM & DMI - & RFV \\
\hline For all groups & $\mathbf{2 3 . 3}$ & $\mathbf{3 6 . 5}$ & $\mathbf{6 8 . 7}$ & $\mathbf{4 . 6}$ & $\mathbf{2 7 2 . 6}$ \\
$S D$ & 13.7 & 19.2 & 13.4 & 2.8 & 196.5 \\
$C V$ & 188.6 & 368.3 & 178.2 & 7.8 & 385954 \\
Min & $\mathbf{4 . 4}$ & $\mathbf{8 . 6}$ & $\mathbf{3 6 . 6}$ & $\mathbf{1 . 5}$ & $\mathbf{5 2 . 1}$ \\
Max & $\mathbf{5 7 . 8}$ & $\mathbf{7 8 . 4}$ & $\mathbf{8 5 . 5}$ & $\mathbf{1 3 . 9}$ & $\mathbf{9 2 3 . 6}$ \\
SE & 1.87 & 2.61 & 1.82 & 0.38 & 9.8 \\
\hline
\end{tabular}

Among the studied parameters characterizing gas production from the different groups of feeds, a number of correlative relationships were identified. The produced gas after $24 \mathrm{hrs}$ incubation correlated very well to NDF content $-r=0.758$ and negatively and strongly with dry matter digestibility $\mathrm{r}=-0.783$ (Table 3 ). The amount of the produced gas after $48 \mathrm{hrs}$ incubation was also associated positively with NDF $(\mathrm{r}=0.691)$ and negatively with dry matter digestibility $(\mathrm{r}=-0.706)$. ADF correlated strongly and positively with NDF- $r=0.735$. Digestible dry matter was negatively correlated to ADF $(r=-0.749)$ and NDF ( $r=$ -0.997) and strongly positively with dry matter intake $(\mathrm{r}=0.801)$. The relative feed value was very strongly related to dry matter intake: $r=0.998$ and to digestible dry matter content: $r=0.786$ although negatively to ADF and NDF contents ( $\mathrm{r}=-0.972$ and $\mathrm{r}=-0.784$, respectively).

This shows that gas production in the rumen of ruminants was primarily dependent on the dietary neutral detergent fibre, acid detergent fibre contents and digestibility, confirming the findings that the production of methane was mainly associated to DM intake, digestibility (i.e. detergent fibre content) and diet composition (Johnson and Johnson, 1995).

Table 3. Correlation coefficients between the parameters of the groups of feeds, $p<0.05$.

\begin{tabular}{lllllllll}
\hline & Groups of feeds & GP 24 h & GP 48 h & ADF \% & DDM & NDF \% & DMI & RFV \\
\hline Groups of feeds & 1.000 & 0.001 & 0.184 & -0.564 & 0.229 & -0.219 & 0.608 & 0.628 \\
GP 24 h & 0.001 & 1.000 & 0.952 & 0.415 & -0.783 & 0.758 & -0.431 & -0.426 \\
GP 48 h & 0.184 & 0.952 & 1.000 & 0.236 & -0.706 & 0.691 & -0.267 & -0.252 \\
ADF \% & -0.564 & 0.415 & 0.236 & 1.000 & $\mathbf{- 0 . 7 4 9}$ & 0.735 & $\mathbf{- 0 . 9 5 9}$ & $\mathbf{- 0 . 9 7 2}$ \\
DDM & 0.229 & $\mathbf{- 0 . 7 8 3}$ & $\mathbf{- 0 . 7 0 6}$ & -0.749 & 1.000 & -0.997 & 0.801 & $\mathbf{0 . 7 8 6}$ \\
NDF \% & -0.219 & $\mathbf{0 . 7 5 8}$ & $\mathbf{0 . 6 9 1}$ & $\mathbf{0 . 7 3 5}$ & $\mathbf{- 0 . 9 9 7}$ & 1.000 & $\mathbf{- 0 . 8 0 4}$ & -0.784 \\
DMI & 0.608 & -0.431 & -0.267 & $\mathbf{- 0 . 9 5 9}$ & $\mathbf{0 . 8 0 1}$ & $\mathbf{- 0 . 8 0 4}$ & 1.000 & $\mathbf{0 . 9 9 8}$ \\
RFV & 0.628 & -0.426 & -0.252 & -0.972 & 0.786 & -0.784 & 0.998 & 1.000 \\
\hline
\end{tabular}

On the basis of correlations, regression equations were composed for approximate determination of the amount of produced gas as a function of the NDF content, digestible dry matter and relative feed value through multiple regression analysis. The coefficient of determination after $24 \mathrm{hrs}$ incubation was $\mathrm{R}=0.890$ (Table 4). The amount of gas produced after $2 \mathrm{hrs}$ could be determined from the dietary $\mathrm{ADF}$ and NDF contents. The coefficient of determination however was rather small $(\mathrm{R}=0.399)$. After $48 \mathrm{hrs}$ of incubation, the same parameters could be also used in multiple regression analysis with coefficient of determination $\mathrm{R}=0.408-0.872$.

Table 4. Regression equations.

\begin{tabular}{|c|c|c|c|c|}
\hline Equation & $\mathbf{R} *$ & SEE & $\mathbf{F}$ & $p<$ \\
\hline GP $24=1275.54-8.312$ NDF-12.253 DDM+0.261 RFW & 0.890 & 465 & 12.66 & 0.0010 \\
\hline GP 24=208.244 +2.11NDF-4.320 ADF & 0.399 & 20.5 & 4.74 & 0.0130 \\
\hline GP $48=1013.11-5.515 \mathrm{NDF}-10.305 \mathrm{DDM}+0.517 \mathrm{RFW}$ & 0.872 & 613 & 10.63 & 0.0020 \\
\hline $\mathrm{RFV}=411.728-8.875 \mathrm{ADF}$ & 0.972 & 13 & 205.1 & 0.0000 \\
\hline $\mathrm{RFV}=349.304-3.330 \mathrm{NDF}$ & 0.784 & 28.5 & 19.11 & 0.0009 \\
\hline $\mathrm{DDM}=88.055-0.829 \mathrm{ADF}$ & 0.853 & 1.8 & 139.21 & 0.0000 \\
\hline $\mathrm{DDM}=93.065-0.667 \mathrm{NDF}$ & 0.959 & 1.1 & 602.14 & 0.0000 \\
\hline
\end{tabular}

$\mathrm{R}^{*}$ - coefficient of determination; SEE- standard error of the estimate; F ratio between parameters; $p<$ level of significance of the equation. 
Apart the amount of produced gas, the values of some other parameters could be also deduced from linear regression models. The RFV could be determined with a sufficient precision from ADF content of feeds $(\mathrm{R}=0.972)$ and through NDF $(\mathrm{R}=0.784)$. The accuracy was better with ADF. The factor analysis of determination of the effects of incubation time and type of feeds showed that gas production was mainly determined by the feeds and their specific features composition, intake, digestibility- $49.86 \%$ (Table 5).
The effect of incubation time was minor - 3.29\%, confirming that not the duration, but the type of the ration was the primary factor for gas production. The effect of tested compound feed and TMR additives Rumanol, Biolife and Bibor was $23.49 \%$. This confirmed the hypothesis that lipid supplements (Grainger and Beauchemin, 2011) and management practices manipulating microbial populations in ruminants (protozoa and methanogens) (Odongo et al., 2007) could reduce the production of methane.

Table 5. Effect of factors hour of determination and groups of feeds on gas production, ml.

\begin{tabular}{lllllll}
\hline Factors & $\begin{array}{l}\text { SS } \\
\text { Sum square }\end{array}$ & $\begin{array}{l}\text { Degrees of } \\
\text { freedom }\end{array}$ & $\begin{array}{l}\text { MS } \\
\text { Mean square }\end{array}$ & F-ratio & $\begin{array}{l}\boldsymbol{p} \text {-level of } \\
\text { significance }\end{array}$ & $\begin{array}{l}\text { \% } \\
\text { Relative share } \\
\text { of factors }\end{array}$ \\
\hline GP (incubation time, h) & 69907 & 1 & 69907 & 13.293 & 0.000345 & 3.29 \\
$\begin{array}{l}\text { Groups of feeds } \\
\begin{array}{l}\text { Feed supplementation with } \\
\text { modulators }\end{array}\end{array}$ & 1059575 & 10 & 105957 & 20.148 & 0.0000. & $\mathbf{4 9 . 8 6}$ \\
GP * Groups of feeds & 56929 & 1 & 56929 & 15.7799 & 0.000238 & $\mathbf{2 3 . 4 9}$ \\
\hline
\end{tabular}

The principal component analysis for the distribution of feeds has shown that straw, fresh feeds, silages, hays and total mixed rations were positive with respect to both factors (Fig. 1, Table 6). Haylages were positive with regard to the $1^{\text {st }}$ factor which describes $77.15 \%$ of the variance and negative for the $2^{\text {nd }}$ factor. Meals, compound feeds and total mixed rations with or without supplements were negative with respect to the two factors.

Table 6. Factor coordinates of cases on the basis of correlations and distribution of feeds by main and additional factors.

\begin{tabular}{lll}
\hline Feeds & Factor $\mathbf{1}$ & Factor 2 \\
\hline 1. Grains & -3.68388 & 2.39137 \\
2. Meals & -1.67184 & -1.72921 \\
3. Straw & $\mathbf{3 . 7 3 8 7}$ & $\mathbf{0 . 3 8 7 2 2}$ \\
4. Fresh feeds & $\mathbf{0 . 8 6 2 3 8}$ & $\mathbf{1 . 0 4 7 4 8}$ \\
5. Silages & $\mathbf{1 . 5 0 3 7 3}$ & $\mathbf{0 . 6 2 7 9 3}$ \\
6. Hays & $\mathbf{1 . 0 7 3 7 9}$ & $\mathbf{0 . 3 2 3 2 3}$ \\
7. Haylages & 2.55804 & -0.78834 \\
8. Compound feeds & -3.21237 & -0.93401 \\
9. Total mixed rations & $\mathbf{0 . 4 4 1 5 1}$ & $\mathbf{0 . 1 3 1 0 2}$ \\
10. Compound feeds + supplements & -1.56397 & -0.76913 \\
11. Total mixed rations + biosupplements & -0.04608 & -0.68758 \\
\hline
\end{tabular}

The studied feeds produce on the average $5.30 \mathrm{ml} / \mathrm{hr}$ gas (Table 7). Grains form the highest amount of gas for an hour $-9.62 \mathrm{ml} / \mathrm{h}$. Then came the fresh feeds, total mixed rations, hays and silages. The least amount of gas is produced by haylages. One percent of ADF corresponded to $9.67 \mathrm{ml}$ gas on the average. The highest amount of gas per $1 \%$ ADF was obtained from grains and compound feeds. One percent NDF corresponded to an average production of $6.48 \mathrm{ml}$ gas.

The production was the highest with grains and compound feeds although lower as compared to ADF.
The average production corresponding to ADF was 3.80 $\mathrm{ml}$, with slightly higher values with grains, fresh feeds, straw and silages. The lowest production was obtained with meals, haylages and total mixed rations with bioadditives. Because the intake of straw was the lowest, it produced the highest amount of gas from an unit of dry matter intake - $129.82 \mathrm{ml}$. High values were obtained with silages, while the lowest - with compound feeds. One unit RFV corresponded to $1.10 \mathrm{ml}$ gas. The highest amount of gas per unit RFV was obtained from straw followed by fresh feeds, while the lowest - from meals and compound feeds. 
PCAndlise for destribution of feeds for gas production and all 7 parameters

Projection of the cases on the factor-plane $\left(\begin{array}{ll}1 \times 2\end{array}\right)$

Cases with sum of cosine square $>=0.00$

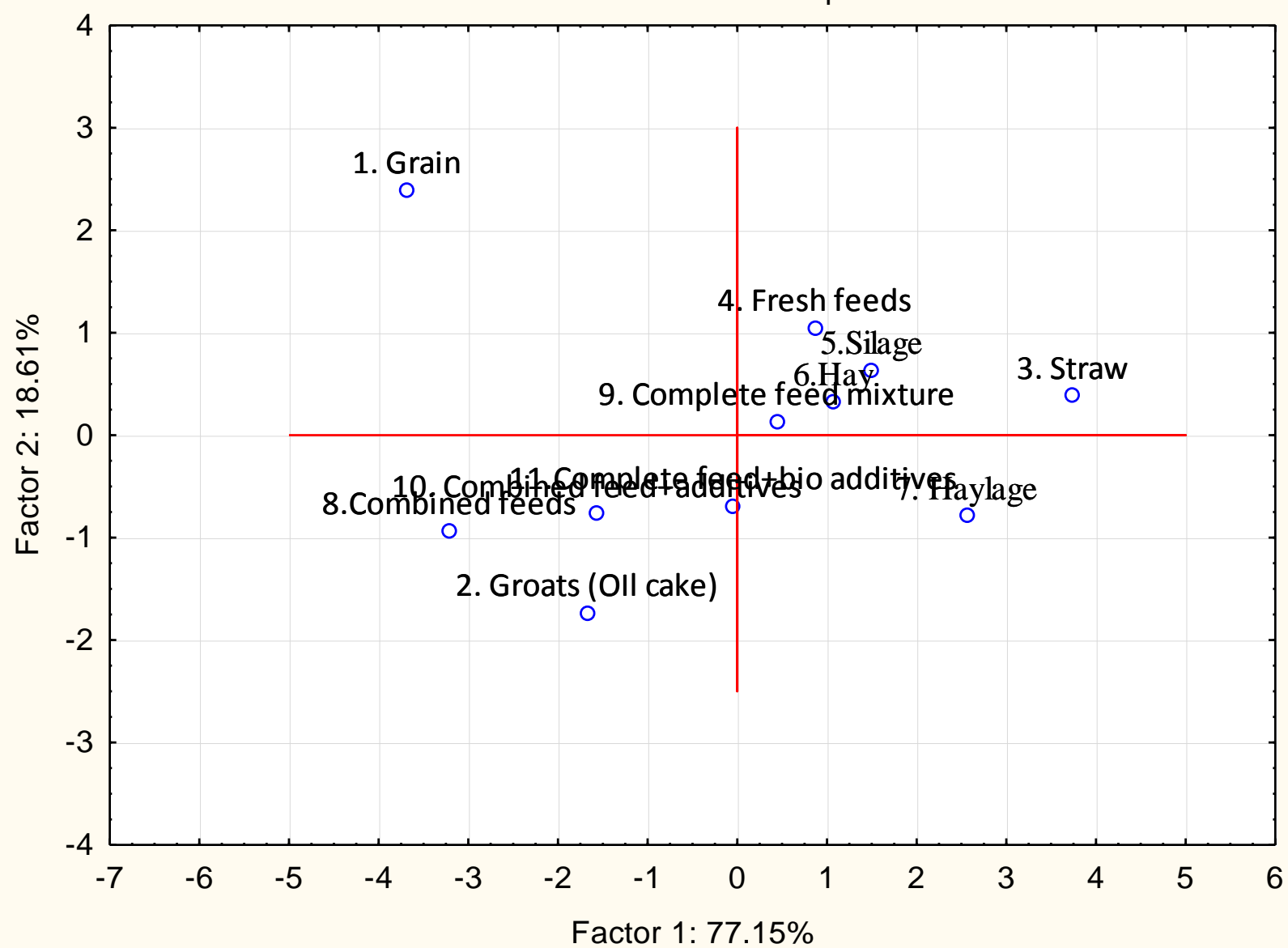

○ Active

Fig. 1: Principal component analysis of the distribution of groups of feeds with respect to gas production for the seven parameters.

Table 7. Gas production indices for the parameters. Gas production per groups of feeds, $\mathrm{ml}$.

\begin{tabular}{|c|c|c|c|c|c|c|}
\hline Groups of feeds & $\begin{array}{l}\text { GP 48h, } \\
\mathrm{ml} / \mathrm{h}\end{array}$ & $\begin{array}{l}\text { GP 48h, } \\
\mathrm{ml} / \mathrm{ADF} \\
\%\end{array}$ & $\begin{array}{l}\text { GP 48h, } \\
\mathrm{ml} / \mathrm{NDF} \%\end{array}$ & $\begin{array}{l}\text { GP 48h, } \\
\mathrm{ml} / \mathrm{DDM}\end{array}$ & $\begin{array}{l}\text { GP 48h, } \\
\mathrm{ml} / \mathrm{DMI}\end{array}$ & $\begin{array}{l}\text { GP 48h, } \\
\text { ml/RFV }\end{array}$ \\
\hline 1. Grains & 9.62 & 74.57 & 20.80 & 5.49 & 85.32 & 1.31 \\
\hline 2. Meals & 4.39 & 12.40 & 9.30 & 2.79 & 31.34 & 0.52 \\
\hline 3. Straw & 4.27 & 3.84 & 2.70 & 4.34 & 129.82 & 3.54 \\
\hline 4. Fresh feeds & 6.01 & 7.43 & 7.22 & 4.91 & 95.80 & 2.11 \\
\hline 5. Silages & 5.40 & 8.17 & 4.67 & 4.60 & 100.10 & 1.99 \\
\hline 6. Hays & 5.00 & 6.94 & 5.43 & 3.87 & 83.00 & 1.70 \\
\hline 7. Haylages & 3.38 & 4.02 & 2.98 & 2.83 & 72.16 & 1.61 \\
\hline 8. Compound feeds & 5.91 & 31.99 & 15.96 & 3.46 & 37.23 & 0.58 \\
\hline 9. Total mixed rations & 5.04 & 10.24 & 5.53 & 3.94 & 67.99 & 1.23 \\
\hline 10. Compound feeds + supplements & 4.98 & 19.32 & 10.11 & 3.02 & 47.08 & 0.77 \\
\hline 11. Total mixed rations + biosupplements & 4.31 & 9.27 & 6.47 & 2.89 & 54.41 & 0.98 \\
\hline Average & 5.30 & 9.67 & 6.48 & 3.80 & 62.87 & 1.10 \\
\hline
\end{tabular}




\section{Conclusions}

1. The amount of produced gas correlated negatively to neutral detergent fibre content ( $\mathrm{r}=-0.691$ to -0.758 ). The relative feed value correlated strongly and positively to dry matter intake $(\mathrm{r}=0.998)$ and digestible dry matter $(r=0.786)$ while negatively with acid detergent fibre and neutral detergent fibre $(\mathrm{r}$ $=-0.972$ and $\mathrm{r}=-0.784$, respectively).

2. The amount of produced gas could be approximately deduced from neutral detergent fibres, digestible dry matter and relative feed value using a multiple regression model $\mathrm{R}=0.872-0.890$. The relative feed value, dry matter intake and digestible dry matter could be obtained from neutral detergent fibres content using regression equations $(\mathrm{R}=0.784-0.959)$.

3. The composition of feeds was the most influential factor for gas production $-49.86 \%$. The treatment of compound feeds and total mix rations with the additives Rumanol, Biolife, Biobor was a factor with $23.49 \%$ influence.

4. The relative feed value, acid detergent fibres exerted the most important effects on gas production rate and gas amount, followed by dry matter intake, neutral detergent fibres and digestible dry matter.

5. Acid- and neutral detergent fibres were found to be essential for reduction of the harmful effect of green house gases from ruminants on the environment, as they both had positive effects on both factors with strongest influence on gas production.

6. The effect of structural fibrous components on dry matter digestibility, dry matter intake and relative feed value was negative. The increase in acid detergent and neutral detergent fibres reduced the dry matter digestibility and relative feed value of feeds, resulting in lower amount of produced gas and lower environmental pollution.

\section{Conflict of interest statement}

Authors declare that they have no conflict of interest.

\section{References}

Beauchemin. K.A., Kreuzer, M., O'Mara, F., McAllister, T.A., 2008. Nutritional management for enteric methane abatement: A review. Aust.J. Exp. Agric. 48, 21-27.
Blümmel, M., Becker, K., 1997. The degradability characteristics of fifty-four roughages and roughage neutral-detergent fibres as described by in vitro gas production and their relationship to voluntary feed intake. British J. Nutr. 77, 757-768.

Ellis, J.L., Kebreab, E., Odongo, N.E., McBride, B.W., Okine, E.K., France, J., 2007. Prediction of methaneproductionfromdairyandbeefcattle. J. Dairy Sci. 90:3456-3467.

Grainger, G., Beauchemin, K.A., 2011. Can enteric methane emissions from ruminants be lowered without lowering their production? Anim. Feed Sci. Tech. 166-167:308-320.

Jeranyama, P., Garcia, A.D., 2004. Understanding Relative Feed Value (RFV) and Relative Forage Quality (RFQ). College of Agriculture \& Biological Sciences / South Dakota State University / USDA. Access at http://agbiopubs.sdstate.edu/articles/ ExEx8149.pdf.

Johnson, K.A., Johnson, D. E., 1995. Methane emissions from cattle. J. Anim. Sci. 73, 2483-2492.

Külling, D.R., Dohme, F., Menzi, H., Sutter, F., Lischer, P., Kreuzer, M., 2002. Methane emissions of differently fed dairy cows and corresponding methane and nitrogen emissions from their manure during storage. Environ. Monit. Assess. 79, 129150.

Leiber, F., Kreuzer, M., Nigg, D., Wettstein, H. R., Scheeder, M.R., 2005. A study on the causes for the elevated n-3 fatty acids in cows'milk of alpine origin. Lipids. 40, 191-202.

Minson, J.D., 1990. Foragein Ruminant Nutrition. Academic Press, San Diego.

Molina-Alcaide, E., Morales-García, E.Y., Martín-García, A.I., Ben Salem, H., Nefzaoui, A., Sanz-Sampelayo, M.R., 2010. Effects of partial replacement of concentrate with feed blocks on nutrient utilization, microbial $\mathrm{N}$ flow, and milk yield and composition in goats. J. Dairy Sci. 93, 2076-2087.

Odongo, N.E., Bagg, R., Vessie, G., Dick, P., OrRashid, M.M., Hook, S.E., Gray, J.T., Kebreab, E., France, J., McBride, B.W., 2007. Long-term effects of feeding mon-ensin on methane production in lactating dairy cows. J. Dairy Sci. 90, 1781-1788.

Reynolds, C.K., Mills, J.A.N., Crompton, L.A., Givens, D.I., Bannink, A., 2010. Ruminant nutrition regimes reduce greenhouse gas emissions in dairy cows. In: Energy and Protein Metabolism and Nutrition (Ed.: Crovetto, G.M.). Wageningen Academic Publ., Wageningen, The Netherlands. pp.427-437. 
Tamburini, A., Colombini, S., Penati, C., Zucali, M., Roveda, P., Rapetti, L., Crovetto, G.M., 2010. Methane emission in livestock and diet characteristics. In: Energy and Protein Metabolism and Nutrition (Ed.: Crovetto, G.M.). Wageningen Academic Publ., Wageningen, The Netherlands. pp.465-466.
Vasta, V., Nudda, A., Cannas, A., Lanza, M., Priolo, A., 2008. Alternative feed resources and their effects on the quality of meat and milk from small ruminants. Anim. Feed Sci. Tech. 147, 223-246.

Ward, R., de Ondarza, M. B., 2008. Relative Feed Value (RFV) vs. Relative Forage Quality (RFQ). Paradox Nutrition, LLC, West Chazy, NY.

\section{How to cite this article:}

Videv, E., Krastanov, J., Laleva, S., Oblakov, N., Angelova, T., Yordanova, D., Kalaydzhiev, D., Oblakova, M., 2017. Influence of some factors on in vitro gas production of different feed groups and possibilities for its prediction.

Int. J. Curr. Res. Biosci. Plant Biol. 4(4), 39-45. doi: https://doi.org/10.20546/ijcrbp.2017.404.007 